\title{
Africa's contribution to the worldwide research literature: New analytical perspectives, trends, and performance indicators
}

\author{
ROBERT J. W. TIJSSEN ${ }^{\mathrm{a}, \mathrm{b}}$ \\ ${ }^{a}$ Centre for Science and Technology Studies (CWTS), Leiden University, Leiden (The Netherlands) \\ ${ }^{\mathrm{b}}$ Centre for Research on Science and Technology (CREST), Stellenbosch University, Matieland \\ (South Africa)
}

\begin{abstract}
This paper examines general characteristics of African science from a quantitative 'scientometric' perspective. More specifically, that of research outputs of Africa-based authors published in the scientific literature during the years 1980-2004, either within the international journals representing 'mainstream' science, or within national and regional journals reflecting 'indigenous science'. As for the international journals, the findings derived from Thomson Scientific's Citation Indexes show that while Africa's share in worldwide science has steadily declined, the share of international co-publications has increased very significantly, whereas low levels of international citation impact persist. A case study of South African journals reveals the existence of several journals that are not processed for these international databases but nonetheless show a distinctive citation impact on international research communities.
\end{abstract}

\section{Introduction}

Many contemporary commentators and analysts argue that scientific research in Africa is now lagging far behind other regions in the world and in dire need of large investments in order to catch up with other developing regions (e.g., HASSAN, 2001; SACHS, 2005; WORLD BANK, 2005). In those cases where African countries appear in international comparative studies of research performance, they usually exhibit very

Received August 7, 2006

Address for correspondence:

ROBERT J. W. TIJSSEN

Centre for Science and Technology Studies (CWTS), Leiden University

P.O. Box 9555, 2300 RB Leiden, The Netherlands

E-mail: tijssen@cwts.leidenuniv.nl

0138-9130/US \$20.00

Copyright (C) 2007 Akadémiai Kiadó, Budapest

All rights reserved 
low ratings (e.g., KING, 2004). These statements and analyses are usually backed up by anecdotal evidence, selected case studies, and R\&D statistics of African countries, all of which are generally recognized to be of limited practical value for truly systematic assessments within and across African countries and fields of science. It is clear that the problems of collecting reliable, up-to-date and truly comparative data on African science at the international level, and making sense of them for policy purposes, presents a huge challenge for the many African countries, especially for those nations that play only a minor role in the world's science. Input statistics of science, such as head counts of researchers, or share of government funding spend on research, would seem to have a practical appeal for analysts and decision-makers alike because several key resources of science can be quantified and statistically analyzed are relatively easy, defined in monetary units (permitting ratios with other economic and financial measures), thus presenting themselves as acceptable proxies for complex phenomena. In practice, even these 'easy' statistics are often problematic, mainly because official national statistics on magnitude and distributions of resources and research personnel are often missing, outdated, or the existing statistics fail to meet international quality standards and statistical manuals.

So, rather than focusing on input statistics, this empirical study focuses on tangible outputs of research. We focus our attention on outputs of basic 'academic' research that are published in the research literature, representing a proxy of the overall output of scientific research to gauge the general health of science systems. An added benefit of this information source is that it may also indicate the existence of scientific research in places and settings where no formal R\&D activity is recorded by national surveys or according to official government statistics.

Four broad categories of research literatures are available in the public domain, each representing a valuable source of information for within-country or cross-country comparisons of scientific capacities and achievements: (I) international peer-reviewed science and engineering journals, and conference proceedings; (II) national or regional peer-reviewed journals and conference proceedings; (III) books and book chapters, and (IV) reports, or other research-based documents. Each of these four research literatures enable analysts to produce external empirical representations and comparative statistics of science, but also allows for categorization and quantification of numerous features of research-based activities, outputs and impacts. Such literature-based quantitative ('scientometric'1) studies on African science are not in great abundance, although the analytical potential of this approach for the developing countries was already recognized and strongly advocated in the 1980s (e.g., FRAME, 1980; BLICKESTAFF \&

\footnotetext{
${ }^{1}$ The subfield of scientometrics deals with measuring and analysing science, which includes 'bibliometric' methods and techniques based on categorizations and measurements of the scientific research literature. For sake of simplicity, the broader term 'scientometric' will be used in the remainder of this paper, rather than term 'bibliometric'.
} 
MORAVCSIK, 1982; GARFIELD 1983; MORAVCSIK, 1985). More recent scientometric research articles dealing in part with Africa, or with specific African countries, include: KonRAD \& WAHL (1990), Chatelin \& ARVANTIS (1992), GAILlARD (1992), SHRUM (1997), and NARVAEZ-BERTHELEMOT et al. (2002). Following up on aggregate-level scientometric data published in the UNESCO series of World Science Reports, ${ }^{2}$ the French Institute de Recherche pour le Développement (IRD) produced a more recent report with some statistics on the state of African science, which covers many African countries but lacks comprehensive cross-country comparisons (WAAST, 2002). The study by ARVANITIS et al. (2000), who used the French PASCAL bibliographic database as a source, is one of the few cases where African countries are systematically compared. Other scientometric studies, such as JACOBS \& INGWERSEN (2000), POURIS (2003; 2005) or INGWERSEN \& JACOBS (2004), provide a welcome measure of quantitative detail on academic research in South Africa, but their scope and coverage of the research literature (category I only) is too constrained to serve as a broad framework for comprehensive cross-country analyses at the African level.

The most recent edition of the United Nations Institute of Statistic's Bulletin on Science and Technology Statistics presents macro-level information on scientific publication output in Africa as a whole for the years 1981-2000 (UIS, 2005). The results of this analysis indicate that Africa represents $1.4 \%$ of the worldwide publication output in 2000, where the share of Sub-Saharan Africa has since the mid-1980s gradually decreased to a level below $1 \%$. This paper has a dual objective: (1) to update and expand the scientometric analyses of the African continent and individual African countries, and (2) to explore the added-value of category II research literature for quantitative analyses of Africa's local research.

\section{Methodology and information sources}

Peer-reviewed scholarly and professional journals are one of the very few internationally comparative sources of information on scientific outputs. This international frame of reference is usually defined by the journals that are processed by Thomson Scientific ${ }^{3}$ for their series of Citation Indexes (CI). These bibliographical databases, indexing the contents of some 9,000 journals, include the Science Citation Index (SCI) and, more recently, their web-based edition Web of Science (WoS).

\footnotetext{
2 The fourth report of this series, 2005 UNESCO Science Report, was published in January 2006.

${ }^{3}$ Formerly known as Thomson ISI, and prior to that, as the Institute for Scientific Information (ISI).
} 
These CI-databases currently provide the most comprehensive and reliable source of information on basic research activity across all countries and fields of science. ${ }^{4,5}$

The bibliographic records of research articles published in CI-listed journals include all author names and all their addresses. Similarly to most of the earlier scientometric studies, 'African science' is represented in this paper by research articles that were (co)authored by Africa-based researchers - i.e. with an affiliate address located in Africa. Virtually all research articles in CI-listed journals will also include footnotes, endnotes, or reference lists that acknowledge the information sources the authors considered to be of some relevance for the research reported in the paper. Our analysis therefore concerns not only the output of those articles, but also the quantities of citations these publications received from other CI-covered articles. The citation impact of these articles is often used as an indicator of international scientific impact, which in turn reflects, to some degree, their scientific relevance and quality. Since the CIdatabases focus on English-language journals with a good international reputation, including the world's most highly cited journals, the coverage of research articles in these CI-listed journals is considered to be adequate for bibliometric studies of most fields of science within the advanced countries. The significance of these 'elite' journals for describing the state of science in Africa is less clear. ${ }^{6}$ Recent studies by BERNARDES \& Albuquerque (2003) and Albuquerque (2004) suggest that CI-based studies enable descriptions of knowledge-generating activities in less developed countries in terms of:

- commitment of individuals or institutions (universities and other knowledge-generating institutions) to engage in basic research activities of an international level;

- local or regional infrastructures that are able to educate, train or host, scholars and researchers who (co-)publish in international peer-reviewed scientific journals;

- capabilities to absorb flows of international scientific and technical knowledge and apply that knowledge in their research.

\footnotetext{
${ }^{4}$ The statistical analyses were done with CWTS's tailored version of Thomson Scientific's Web of Science (WoS), which fully indexes some 8,000 international peer-reviewed science and engineering journals. It offers worldwide coverage of research fields, as well as adequate coverage of mainstream science in African countries. The database covers the years 1980 up and to and including the most recent publication year (2005).

${ }^{5}$ The journals attributed to the broad and very heterogeneous field of the Arts and Humanities are excluded through the paper, mainly because these CI-listed journals in this field do not provide a reliable representation of research capabilities or outputs in this field.

${ }^{6}$ Some results of the case study presented in this paper suggest the existence of non CI-listed South African journals with a significant citation impact on worldwide science. This outcome could indicate that important segments of South Africa science are not adequately represented in the CI-databases. This particular finding is discussed in-depth Mouton et al. (2006) and TIJSSEN et al. (2007).
} 
As more and more of the international and domestic research literature is added to journal-based bibliographic databases nowadays, the validity of this scientometric approach is indeed likely to increase, as does the strategic relevance of CI-based scientometric findings. The next section presents statistical information on output and citation impact of African research published in 'main stream' CI-listed journals, followed by case study that explores the added value of information on output and citations of African research articles that were disseminated in 'peripheral' domestic or regional journals.

\section{African science in international journals}

\section{General developments and trends}

Africa's long-term publication output trends indicate that its contribution to global knowledge production has slipped slightly during the 1990s. Sub-Saharan Africa has fallen behind quite dramatically; from a $1 \%$ share in 1987 to $0.7 \%$ in 1996 , with no sign of recovery (Figure 1). Africa has lost $11 \%$ of its share in global science since its peak in 1987; Sub-Saharan science has lost almost a third $(31 \%) .{ }^{7}$ One of the main reasons for this decline is the lack the resources in many African countries, and the willingness to invest in infrastructure and modern equipment in order to retain workers at universities, research laboratories and health institutions. Many researchers suffer from poor working environments, low pay, a lack of equipment and career prospects, which are damaging morale among African researchers and encouraging people to migrate to industrialized nations.

It is important to keep in mind that these diminishing shares of African science do not reflect a decrease in an absolute sense, but rather an increase less than the worldwide growth rate. During the last 15 years, African output has in fact risen by $38 \%$, up to some 46,000 articles in 2001-2004. The countries in Northern African Egypt and the Maghreb countries (Algeria, Mauritania, Libya, Morocco and Tunisia) accounted for the modest growth of the African share of the worldwide output during the years 1998-2002.

Another explanation for the very significant decline of Sub-Saharan publication output is the removal of African journals from the Citation Indexes; for example, the number of South African journals dropped from 35 to 19 during the years 1993-2004.

\footnotetext{
${ }^{7}$ ARVANITIS et al. (2000) found similar rates of decline within the PASCAL database, in large part due to the cancellation of several African journals in PASCAL, notably those from Egypt and South Africa.
} 


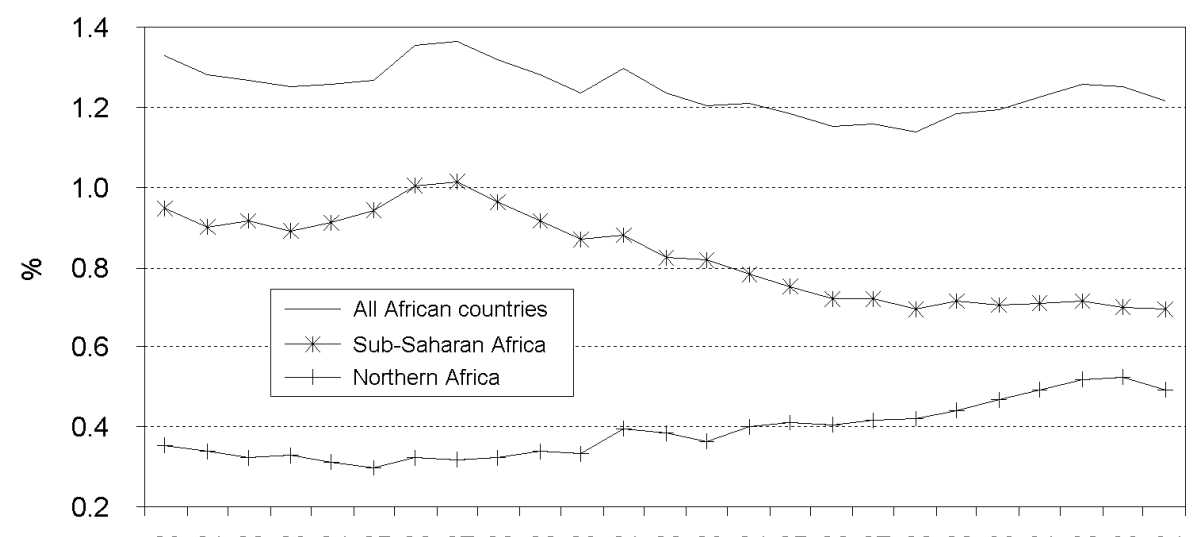

80818283848586878889909192939495969798990001020304

Figure 1. Trends in African research article output in the international journal literature (1980-2004): $\%$ of worldwide publication output in the international peer-reviewed journal literature. Source: CWTS/Thomson Science Citation Index database (edition 2005, excluding the Arts and Humanities Citation Index).

When examining African science, especially in the less developed countries, one obviously needs to take into account the role of international scientific cooperation. By using the author addresses listed in the bylines of research articles, one can identify countries and organizations where the authors were employed at the time when the research was done and/or the article was written. Institutionally co-authored research articles co-publications are useful and tangible proxies of research involving African scientists and scholars. ${ }^{8}$ These co-publications can be used to systematically gauge patterns of scientific cooperation within and between institutes and countries. Three mutually exclusive categories of articles are discerned: (a) international cooperation two or more different countries, including at least one African country, are listed in the author addresses; (b) domestic cooperation - one African country with two or more different 'main organizations'; (c) 'single institute' papers - i.e. only one African country and one main organization mentioned.

\footnotetext{
${ }^{8} \mathrm{~A}$ fair share of the internationally co-authored publications can be attributed to genuine international cooperation, where researchers share and exchange ideas, resources and facilities. Part of it will result from non-African scientists and scholars with dual appointments, or those researchers on working visits and temporary stays in African countries (e.g. for field work) that list both their home address and temporary address, and vice versa in the case of scientists with a home country in Africa.

${ }^{9} \mathrm{~A}$ 'main organization' refers to the highest aggregate level of the organisational entity, e.g. the entire university, government research institute, parent company, or research council.
} 


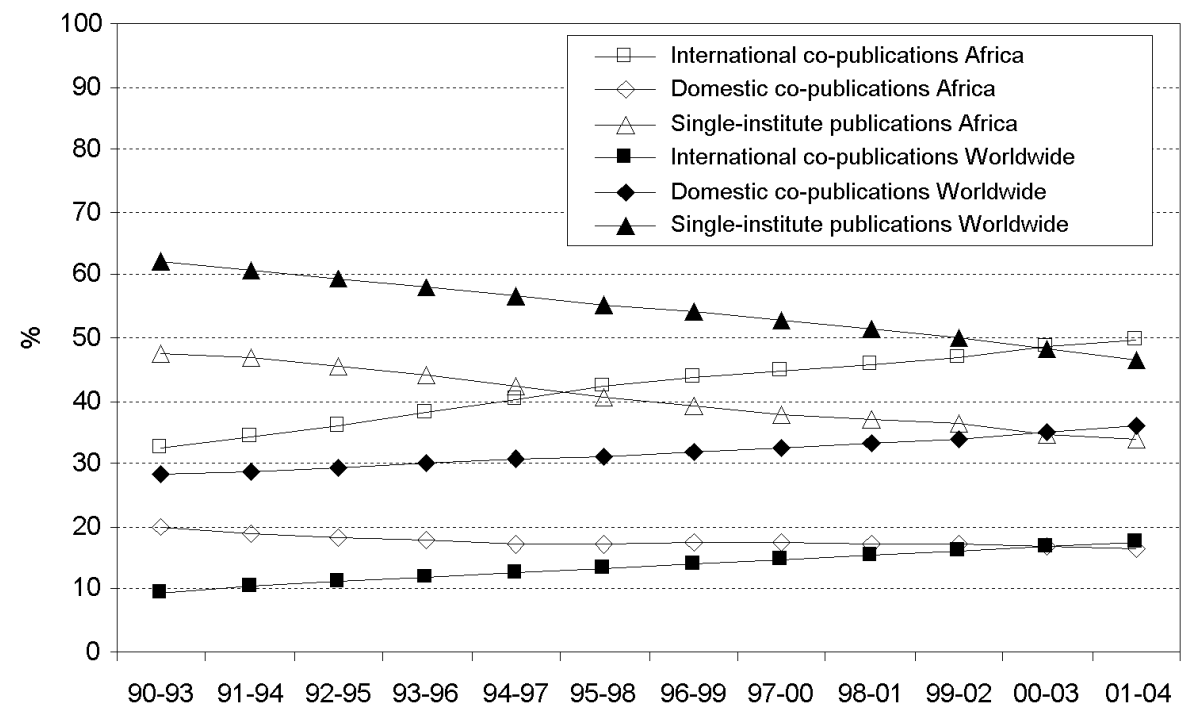

Figure 2. African trends versus worldwide trends in publication output by type of research cooperation (\% of share co-authored publications within the total output; rolling 4-year averages).

Source: CWTS/Thomson Science Citation Index database (edition 2005, excluding the Arts and Humanities Citation Index).

Figure 2 exhibits the trends in scientific output across a series of moving four year periods according to this categorization of research articles. Internationally co-authored papers were the major contributor to this increase; the share of the international copublications has risen very significantly, from $30 \%$ in the early 1990 's up to $50 \%$ in recent years, exceeding the worldwide growth of these co-publications which now make up some $18 \%$ of the total publication output worldwide. The African continent is very heterogeneous in terms of the international orientation of its national science systems. The share of co-publications in the total publication output of individual African countries, shown in Table 1, show very significant differences, ranging from $29 \%$ in the case of Egypt and 39\% in South Africa, to staggering 85\% in Mali and 87\% in Gabon.

While the numbers of 'single institute' papers from African countries remain stable at $15 \%$ of the total African output, the share of the domestically co-authored Africa papers has steadily declined from $48 \%$ to $34 \%$. In contrast, domestic scientific cooperation has increased significantly worldwide. ${ }^{10}$ The marked differences between African trends and worldwide developments suggest African scientists have gradually

\footnotetext{
${ }^{10}$ Similar worldwide statistics published in the US Science and Engineering Indicators Report 2006, indicate that the share of internationally co-authored articles has risen from $8 \%$ in 1988 to $20 \%$ in 2003 . Simultaneously, the share of single institute papers dropped from $60 \%$ to $42 \%$ (NSB, 2006).
} 
adopted research strategies, especially in the case of basic research that is published in international journals, in which reliance on foreign partners and contributions have become a dominant factor. The extremely high share of international co-publications may indicate a structural dependence of African science, owing to the resources offered by advanced countries to help alleviate infrastructural and financial constraints are hampering many African science systems.

\section{International citation impact}

In the light of the increasing numbers of African research articles in international journals, and the rising share of international co-publications, it seems reasonable to assume that African science is becoming increasingly internationalized. This trend has yet to visibly pay off in terms of higher levels of international citation impact. The timeseries depicted in Figure 3 indicates that the 'relative citation impact score' 11 of African international co-publications has remained fixed a level of about 0.9 during the last 15 years - i.e. a score $10 \%$ below the worldwide average level.

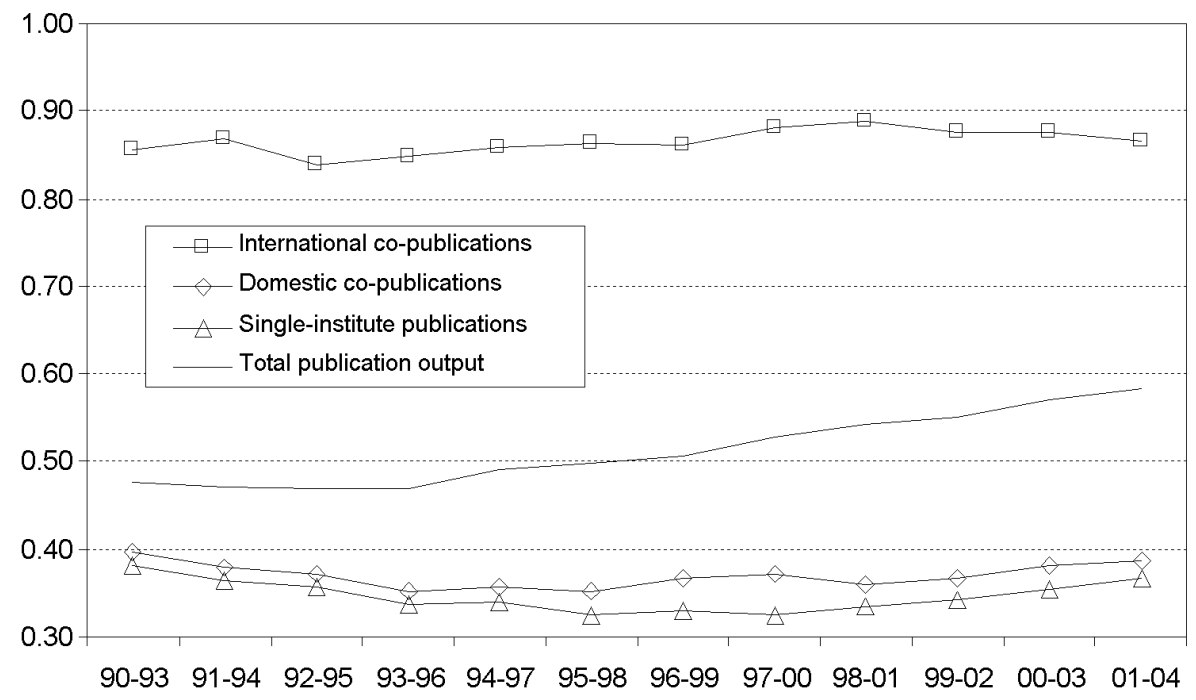

Figure 3. Trends in citation impact of African research articles* Source: CWTS/Thomson Science Citation Index database (edition 2005, excluding the Arts and Humanities Citation Index).

* Field normalized citation impact scores (worldwide average score $=1.0$ )

\footnotetext{
11 The 'field-normalized citation impact score' is the ratio of the average citation frequency of a set of research articles, produced by an entity within a specified time-interval, and the worldwide averages in the respective fields of science during the same time period (see the legend of Table 2 for more details).
} 
The relative citation impact scores of the domestic co-publications and the single institute papers have also hardly changed, albeit at much lower levels of about 0.6. Earlier bibliometric studies have shown that international co-publications in CI-listed journals tend to, on average, receive relatively large numbers of citations compared to other publications within the same fields of research (e.g. NARIN et al., 1991) - this also appears to be the case for CI-papers with African co-authors.

Overall, the citation impact scores are significantly below worldwide average, indicating a continent-wide low degree of visibility and impact of African science within the international scientific community. This outcome does not necessarily always imply that mediocre science is being carried out across Africa, or that African scientists are second-rate. It is more likely to reflect the use of outdated and inadequate research facilities and infrastructures, and a lack of incentive structures and career prospects that reward (international) research performance and scientific quality. Moreover, these average citation scores obscure the large measures of statistical variance within the data. In fact, some African countries perform close to, or slightly above, worldwide average (see Table 1).

\section{Research performance of African countries}

The catch-all term 'African science' covers a broad collection of African nations with very heterogeneous set of research systems in terms of size, human and financial resources, scientific specialization, general objectives, and local governance structures. As far as scientific capabilities and research performance of individual African countries are concerned, detailed studies by WAAST (2002) reveal that some countries in Sub-Saharan Africa, such as Nigeria, have regressed in many fields of science. In other countries, whole areas of expertise have virtually disappeared, such as agricultural sciences in Kenya and Côte d'Ivoire. A further breakdown of the publication output indicates that, despite their positive growth rate, the most recent developments of the largest African countries are best described as 'leveling off', or 'steady state'.

Figure 4 makes it abundantly clear that only Algeria and Tunisia have been able to generate noticeable growth during the years 2001-2004. South Africa's gradual increase seems to have come to a halt in 2002. If this state of affairs persists during the next few years, most of Africa's scientific 'powerhouse' nations are likely to fall further behind comparator countries, like the 'Asian Tigers' (Taiwan, Singapore, Korea, Malaysia), that have embarked on economic catch-up trajectories, countries that do manage to achieve prolonged significant growth through sustained capacity-building, investments, and upgrading of their science bases. 


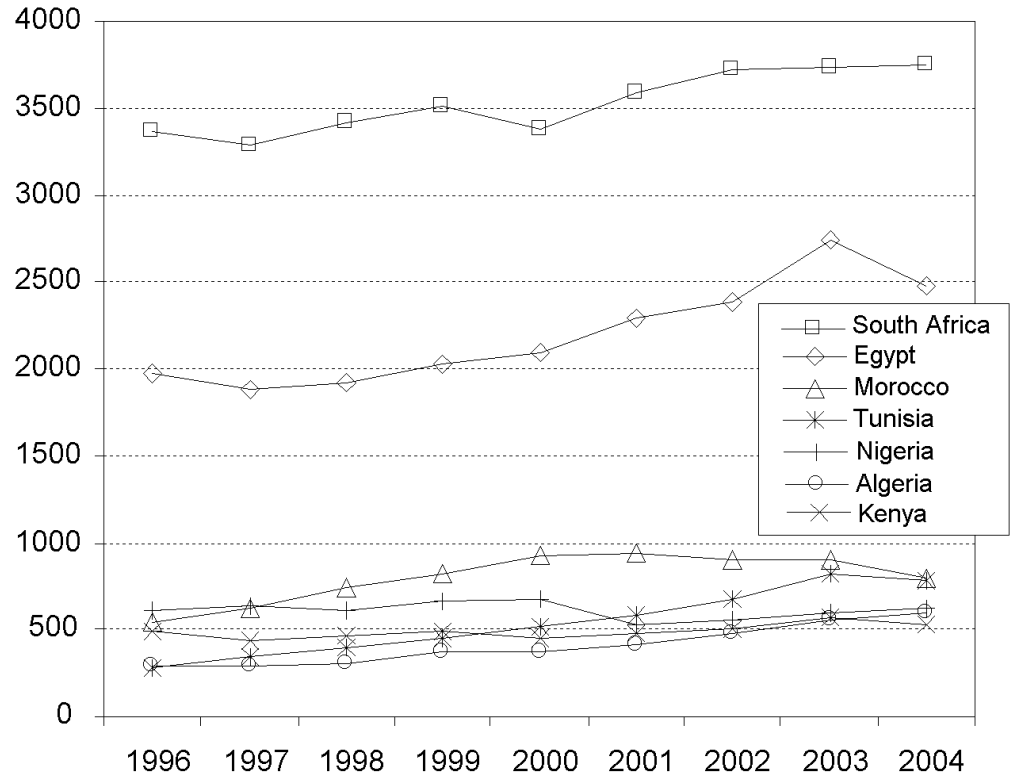

Figure 4. Recent trends in publication output of major African countries* Source: CWTS/Thomson Science Citation Index database (edition 2005, excluding the Arts and Humanities Citation Index).

Table 1 displays the most recent output and impact data at the level of the individual African nations, disclosing many significant differences between those countries. In terms of equal spread of output across the continent, the term 'African science' is somewhat of a misnomer. Africa's output in the international journal literature is extremely skewed; the largest country (South Africa) accounts for more than $31 \%$ of Africa's publication output, and the first and second country (Egypt) jointly account for $52 \%$.

Secondly, interesting deviations are found between countries with similar levels of scientific and technological development (as measured by the ArCo index, ARCHIBUGI \& COCO, 2004; 2005). ${ }^{12}$ Overall, a significant positive correlation is found between the ArCo-index of the African countries and their total publication output (Pearson correlation coefficient $\mathrm{r}=0.51$ ). However, the total publication output can be a misleading performance measure; countries with similar output levels, or ArCo scores, may exhibit very different research performance profiles.

\footnotetext{
12 The ArCo index values relate to 1999-2000 and include 162 countries. The ArCo index comprises of eight sub-indexes: patents; scientific articles; technology creation; internet penetration; telephone lines and mobiles; electricity consumption; technological infrastructure; human skills and resources.
} 
Table 1. Bibliometric performance profiles of African countries: summary statistics (2001-2004)***

\begin{tabular}{|c|c|c|c|c|c|c|c|}
\hline \multirow[b]{2}{*}{ Country } & \multirow{2}{*}{$\begin{array}{l}\text { ArCo } \\
\text { index }\end{array}$} & \multirow{2}{*}{$\begin{array}{c}\text { Total publ. } \\
\text { output }\end{array}$} & \multirow{2}{*}{$\begin{array}{l}\% \text { int. } \\
\text { co-publ. }\end{array}$} & \multirow{2}{*}{$\begin{array}{c}\text { Citation rate } \\
\text { per publ. }\end{array}$} & \multirow{2}{*}{$\begin{array}{l}\% \text { cited } \\
\text { publ. }\end{array}$} & \multicolumn{2}{|c|}{ Relative citation scores*** } \\
\hline & & & & & & Field-norm. & Journal-norm. \\
\hline South Africa & 0.37 & 14809 & 39 & 1.56 & $40 \%$ & 0.63 & 0.90 \\
\hline Egypt & 0.27 & 9895 & 29 & 0.81 & $31 \%$ & 0.45 & 0.78 \\
\hline Morocco & 0.22 & 3535 & 56 & 0.82 & $30 \%$ & 0.43 & 0.69 \\
\hline Tunisia & 0.29 & 2857 & 48 & 0.75 & $26 \%$ & 0.44 & 0.68 \\
\hline Nigeria & 0.14 & 2309 & 30 & 0.86 & $24 \%$ & 0.47 & 0.78 \\
\hline Kenya & 0.20 & 2067 & 74 & 1.89 & $45 \%$ & 0.8 & 0.80 \\
\hline Algeria & 0.28 & 2028 & 58 & 0.73 & $23 \%$ & 0.51 & 0.70 \\
\hline Cameroon & 0.19 & 896 & 73 & 1.28 & $37 \%$ & 0.64 & 0.80 \\
\hline Tanzania & 0.16 & 855 & 78 & 1.84 & $46 \%$ & 0.87 & 0.85 \\
\hline Ethiopia & 0.07 & 767 & 61 & 1.19 & $35 \%$ & 0.53 & 0.69 \\
\hline Zimbabwe & 0.28 & 735 & 66 & 1.40 & $42 \%$ & 0.64 & 0.82 \\
\hline Uganda & 0.13 & 724 & 74 & 2.23 & $46 \%$ & 0.95 & 0.97 \\
\hline Ghana & 0.20 & 641 & 65 & 1.68 & $39 \%$ & 0.78 & 0.86 \\
\hline Senegal & 0.15 & 618 & 74 & 1.42 & $38 \%$ & 0.74 & 0.82 \\
\hline Ivory Coast & 0.14 & 449 & 73 & 1.46 & $37 \%$ & 0.75 & 0.81 \\
\hline Botswana & 0.26 & 422 & 41 & 0.98 & $30 \%$ & 0.53 & 0.75 \\
\hline Malawi & 0.13 & 413 & 73 & 2.08 & $49 \%$ & 0.76 & 0.78 \\
\hline Burkina Faso & 0.05 & 364 & 80 & 1.50 & $40 \%$ & 0.69 & 0.82 \\
\hline Sudan & 0.14 & 315 & 63 & 1.44 & $40 \%$ & 0.68 & 0.92 \\
\hline Zambia & 0.24 & 286 & 80 & 2.03 & $49 \%$ & 0.75 & 0.71 \\
\hline Madagascar & 0.12 & 284 & 83 & 1.52 & $40 \%$ & 0.75 & 0.87 \\
\hline Gambia & 0.12 & 273 & 87 & 3.35 & $64 \%$ & 1.07 & 0.89 \\
\hline Benin & 0.11 & 257 & 81 & 1.13 & $34 \%$ & 0.68 & 0.79 \\
\hline Gabon & 0.23 & 240 & 87 & 2.74 & $55 \%$ & 0.85 & 0.89 \\
\hline Mali & 0.07 & 190 & 84 & 3.87 & $42 \%$ & 1.09 & 0.83 \\
\hline Libya & 0.31 & 161 & 51 & 0.81 & $27 \%$ & 0.58 & 0.32 \\
\hline Mauritius & 0.29 & 153 & 53 & 1.56 & $26 \%$ & 0.63 & 0.43 \\
\hline Namibia & 0.22 & 145 & 56 & 1.93 & $34 \%$ & 0.48 & 0.31 \\
\hline Congo Rep. & 0.21 & 135 & 79 & 1.26 & $34 \%$ & 0.75 & 0.53 \\
\hline Niger & 0.03 & 126 & 66 & 1.53 & $40 \%$ & 0.87 & 0.56 \\
\hline Mozambique & 0.10 & 118 & 82 & 2.63 & $36 \%$ & 0.85 & 1.06 \\
\hline Togo & 0.15 & 101 & 66 & 0.99 & $33 \%$ & 0.63 & 0.47 \\
\hline
\end{tabular}

Source: CWTS/Thomson Science Citation Index database (edition 2005, excluding the Arts and Humanities Citation Index).

* Selected countries with at least 100 publications in CI-listed journals in the period 2001-2004.

** All citation statistics refer to cited and citing publications in the years 2001-2004.

*** The relative citation scores refer to the extent in which a specific set of journal publications are cited more $(>1)$ or less $(<1)$ than the average citation rate of all publications worldwide within either the same set of journals, or the corresponding set of fields of science. These fields are equivalent to the Journal Categories defined by Thomson Scientific for its Citation Index (CI) databases. Field-normalized relative citation score is defined as the average citation frequency per paper of an entity's publication output is compared to the weighted average citation rate of the set of fields in which the unit has published (excluding author selfcitations in all computations). The worldwide citation rate per field is set at unity; scores above 1 indicate a citation impact rate above field average. Journal-normalized relative citation scores: similar to the fieldnormalized relative citation rate, but at the level of the collection of CI-listed journals in which the entity has published. 
Within the group of the seven largest countries, South Africa and Kenya are clearly outperforming the other five in terms of average citation rates, the share of publications cited, and the field-normalized citation scores. It seems reasonable to assume that this performance is partly a cultural heritage from their English-language science systems that help sustain or enhance their visibility in English-language-dominated international research literature. The Northern African countries, traditionally more focused on the Arab world and the French-speaking scientific world, are at a disadvantage. This bias in favor of the English research literature is (partially) corrected by applying the journalnormalized citation impact score, which introduces a more restricted 'like with like' comparison at the level of sets of journals that researchers in specific countries tend to favor for publishing their findings (rather than using the full set of CI-listed journals in a field as a frame of comparison). Going down the list, we find a few countries, like Gambia, Mali and Mozambique, producing few publications but managing to attract relatively large numbers of citations; either their field-normalized score or journalnormalized score are well above the worldwide average (score 1.0).

A country's research capacity to produce international science is, as one would expect, closely linked to its level of scientific and technological development, but is inversely related to international citation impact. One of the main reasons for this paradox is the relative high citation impact of international co-publications (see Figure 2); the correlation coefficient between the share of international co-publications within the African countries and their field-normalized citation score equals $r=0.77$. The correlation coefficient for the journal-normalized citation scores is $\mathrm{r}=0.32$, indicating that the citation impact of country's international co-publications depends heavily on the choice of international journals for publishing. Most of the international cooperation occurs within fields of the medical and life sciences. This finding brings up the issue of a country's research specialization profile, which will be discussed in the next section.

\section{Research specialization of African countries}

The international research performance of African countries is partially dependent upon their research specialization profile. Some fields of science, like the medical sciences, are internationally oriented and tend to attract more international funds, partnerships, and opportunities to publish in the international scientific literature. Other fields, like the engineering sciences and social sciences, tend to have a much larger focus on local issues and areas of interest, as a result of which research articles are more often published in local scientific and professional journals. Based on the information presented in Table 2, one can, very crudely, distinguish at least four clusters of African countries according to their research specialization profiles. Kenya is the only one of the more highly developed African countries with a strong concentration of international research within medical and life sciences. 
Table 2. Research specialization profiles of African countries (2001-2004)*

\begin{tabular}{|c|c|c|c|c|}
\hline \multirow[b]{2}{*}{ Country } & \multicolumn{4}{|c|}{ Share of CI-listed research articles by broad field of science (in \%) } \\
\hline & Medical \& Life sciences & Natural sciences & Engineering sciences & Social sciences \\
\hline Gambia & 96 & 1 & 0 & 3 \\
\hline Gabon & 88 & 10 & 0 & 2 \\
\hline Malawi & 86 & 6 & 1 & 8 \\
\hline Mali & 83 & 7 & 0 & 10 \\
\hline Togo & 81 & 15 & 2 & 1 \\
\hline Uganda & 78 & 11 & 1 & 10 \\
\hline Congo Rep. & 77 & 19 & 2 & 2 \\
\hline Ivory Coast & 75 & 17 & 2 & 6 \\
\hline Kenya & 75 & 16 & 2 & 7 \\
\hline Benin & 73 & 20 & 2 & 4 \\
\hline Burkina Faso & 73 & 16 & 4 & 7 \\
\hline Zambia & 72 & 14 & 5 & 9 \\
\hline Tanzania & 70 & 15 & 6 & 8 \\
\hline Senegal & 70 & 19 & 5 & 6 \\
\hline Sudan & 69 & 23 & 5 & 3 \\
\hline Ethiopia & 69 & 22 & 2 & 7 \\
\hline Madagascar & 65 & 29 & 1 & 5 \\
\hline Mozambique & 64 & 18 & 7 & 11 \\
\hline Cameroon & 63 & 27 & 5 & 5 \\
\hline Zimbabwe & 61 & 21 & 6 & 13 \\
\hline Ghana & 60 & 18 & 8 & 14 \\
\hline Nigeria & 54 & 27 & 9 & 9 \\
\hline Niger & 53 & 32 & 11 & 4 \\
\hline South Africa & 50 & 31 & 10 & 9 \\
\hline Mauritius & 46 & 39 & 10 & 6 \\
\hline Libya & 41 & 30 & 26 & 3 \\
\hline Namibia & 39 & 48 & 2 & 12 \\
\hline Tunisia & 33 & 49 & 16 & 2 \\
\hline Egypt & 27 & 52 & 20 & 1 \\
\hline Botswana & 26 & 44 & 6 & 25 \\
\hline Morocco & 24 & 57 & 18 & 1 \\
\hline Algeria & 14 & 57 & 28 & 1 \\
\hline Africa & 61 & 25 & 7 & 7 \\
\hline Worldwide & 44 & 37 & 13 & 7 \\
\hline
\end{tabular}

Source: CWTS/Thomson Science Citation Index database (edition 2005, excluding the Arts and Humanities Citation Index).

* Selected countries that produced at least 100 publications in CI-listed journals during the period 2001-2004.

Secondly, Northern Africa's 'Maghreb' countries tend to be much more active in the engineering science, in part owing to publication output by researchers at the Frenchstyle engineering schools and technical universities with a long-standing academic tradition of publishing (WAAST, 2002).

Overall, we find a very significant over-representation of the medical and life sciences in African research articles (61\% compared to $44 \%$ worldwide) and underrepresentations in the natural sciences $(25 \%$ vs. $37 \%)$ and engineering sciences ( $7 \%$ vs. 
$13 \%)$. The African focus on medical and life sciences is a consequence of the research work on tropical deceases and many health problems in sub-Saharan Africa. The location of international medical research centers on African soil, and the abundance of international research cooperation between African researchers and those overseas, contributes to this overrepresentation, but also to the international visibility and scientific impact of African science as a whole, as illustrated in Figures 1 and 4.

But to what extent are these country profiles a reliable representation of all journal articles produced by a country? More generally speaking, is the international publication output of an African country a good proxy for the size and composition of its science system? The next section provides some answers to those questions, with a special focus on the South Africa (SA).

\section{Africa's 'hidden' science base: research articles in domestic and local journals}

\section{General introduction and overview}

Nobody would disagree that the printed outputs of local African science are underpresented in international statistics on science. For one, the vast majority of Africa's science journals are excluded from the CI-databases or processed selectively. Out of a total of 7,681 journals listed in the Science edition and/or Social Sciences edition of Thomson Scientific's Journal Citation Reports 2004, a mere 0.3\% are African journals (i.e. 23 journals). GAILLARD (1996) argues that some 65\% of African research papers are published in local journals that are not listed in the international citation databases. Clearly, only a very small fraction of Africa's peer-reviewed serial literature is CIlisted. This state of affairs is unlikely to improve unless African journals succeed to raise their international visibility; Thomson Scientific tends to select new journals explicitly on the basis of their international standing, one of the key criteria being the citation impact of a journal's articles on the research literature in CI-listed journals. A slightly larger percentage Africa's local science and technology journals enjoys some international visibility by being (fully) covered in other large international databases. ${ }^{13}$

Most of Africa's journals are predominantly meant for local purposes, they tend to have relatively low circulation rates, and many are published irregularly.

\footnotetext{
${ }^{13}$ The precise number of African journals is current unknown; African Journals Online lists 229 journals on its site (November 2005), Ulrichs Periodical Directory lists 327 peer-reviewed journals (2004 edition), and INASP (International Network for the Availability of Scientific Publications) estimate the total number of Sub-Saharan journals in the range of 900-1000 (cf. SMART, 2005).
} 
Still, there are several very good reasons for African researchers to publish in these local journals rather than in peer-reviewed foreign journals. ${ }^{14}$ Many of these locallyoriented periodicals represent a distinct niche in the domestic or regional science base, covering one or more topical areas within research fields, and often representing professional societies, specific research institutes, or research funding agencies (e.g. an academy of science). In many cases, these journals act as focal points of local research communities and are considered prime outlets of research outputs. Many employ peerreviewed based selection procedures of journal manuscripts by way of quality control mechanisms.

To what degree do these 'flagship' journals also contribute to the international visibility of African science? Which of them could be candidates to bridge the divide between local science and the international research frontiers, and, in the process, achieve sufficiently high levels of international visibility to possibly become a CI-listed journal? One way of addressing this question is to examine the citation impact of African research articles published in non CI-listed journals on the international research literature as represented in the CI-listed journals. The information source is one of Africa's major repositories of science and technology journals: the African Journals OnLine database (www.ajol.info), a compilation of 228 scholarly journals (viewed on November $24^{\text {th }} 2005$ ) that are edited and/or published in Africa, or with content dealing with Africa (SMART, 2005). ${ }^{15}$ Although most of the AJOL-indexed journals are not CIindexed, research articles published in AJOL journals are cited by articles in CI-listed journals. These citations can therefore be used to gauge the visibility of domestic African science within the international scientific literature. ${ }^{16} \mathrm{~A}$ citation analysis was

\footnotetext{
${ }^{14}$ For instance, a study by POURIS \& RICHTER (2000) among South African scientists and scholars list the following reasons for publishing in the 'local' South African journals: the paper did not meet the scope or quality standards of an international peer-reviewed journal; the journal as the best outlet for the paper; a special issue of the journal focusing on domestic or regional issues or problems; papers on a topic or domestic or regional significance; the paper is targeted towards a regional or domestic audience; rapid publication times; the wish to contribute to support a local journal and/or encourage local scholarship; concerns an accredited journal where publications yield output-based governments subsidies.

${ }^{15}$ African Journals OnLine began in May 1998 as a pilot project managed by INASP (International Network for the Availability of Scientific Publications). It aimed to promote the awareness and use of Africanpublished journals in the sciences by providing access to tables of contents on the Internet, backed by a document delivery service. AJOL-indexed journals cover the agricultural sciences and resource management, arts, culture, language and literature, health science and technology, and social sciences. The National Inquiry Services Centre (NISC) of South Africa has taken over management of AJOL in 2005. AJOL records contain a range of information on each journal, including its sponsor, publisher, editor or co-editors, subject field, language(s) of publication, country and city of focus.

${ }^{16}$ This citation analysis will deal only with the aggregate level of journals as a whole, rather than at the level of individual publications in those journals, based on bibliographical information from the 'non-source' citations in the Thomson Scientific CI-databases, as processed for their Web of Science database. These entries may include the full titles of journals, but often comprise of a wide variety of author-given or Thomson Scientific-generated truncations, acronyms and misspellings that may or may not refer to these journals. The cleaning, matching and standardization procedure was done at CWTS.
} 
performed on the 'non-source' citations within the CI-listed journals to identify cited AJOL-indexed non-CI journals. The publication years of the citing literature was 2001-2004; the cited publications years were 1980-2004.

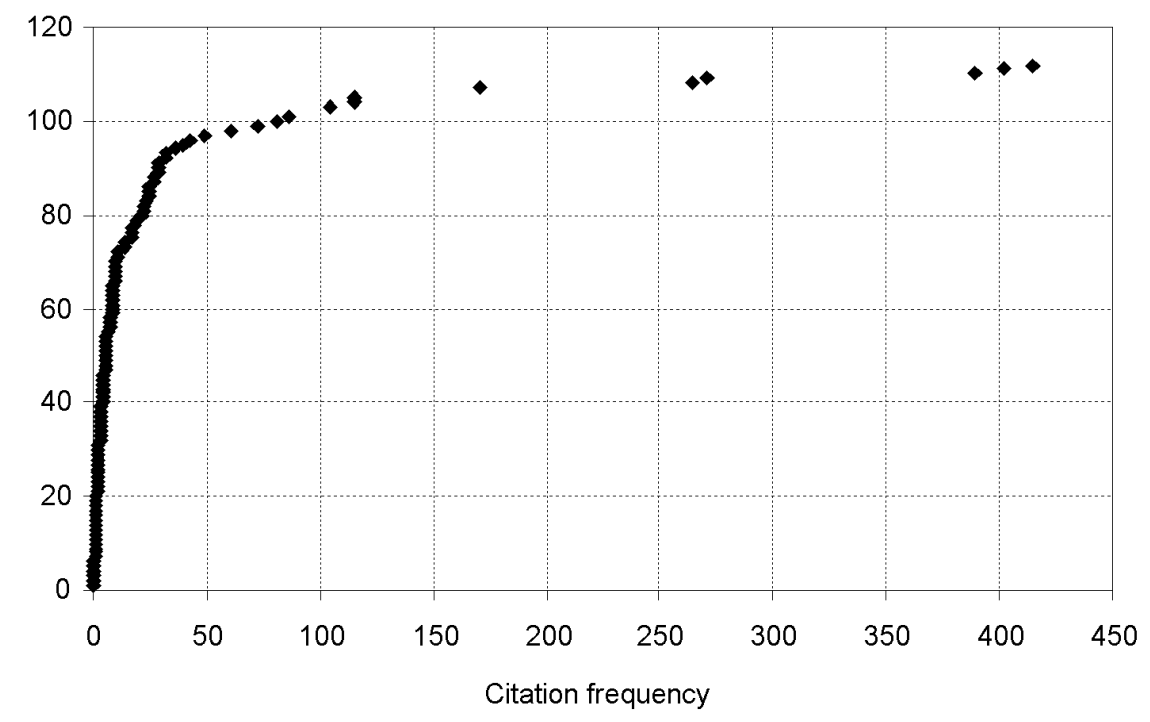

Figure 5. Distribution of number of citations received by non-CI listed AJOL-indexed journals $(\mathrm{n}=111)^{*}$ * Sources: African Journals OnLine database (viewed on November 24th 2005); CWTS/Thomson Science Citation Index database (edition 2005, excluding the Arts and Humanities Citation Index). Citing publication years: 2001-2004; cited publication years: 1980-2004.

Figure 5 displays the citation frequency distribution. More than half of the selected AJOL journals $(n=112)$ were not cited during this time-interval, ${ }^{17} 50$ of them received only 1-5 citations, and no more than 12 journals, including five SA journals, received at least 100 citations. The dominant position of South Africa is also visible in the top-5 most highly cited journals, in descending order: South African Forestry Journal (SA), Philosophical Papers (SA), West African Journal of Medicine (Nigeria), Quaestiones Mathematicae (SA), and African Journal of Range and Forage Science (SA). These particular journals would seem to have published research articles that generated a noticeable impact on articles published in CI-listed research literature. However, a fuller appreciation of their impact on the international research literature should take note of the fact that citation frequencies may critically depend on several determinants, not least the volume of papers published in a journal, but also the field of science, and the degree

${ }^{17}$ That is, no conclusive evidence of such references could be found among the many hundreds of thousands of entries in the reference lists in the Web of Science database. 
of self-citations where authors refer to their previous articles in international journals. These issues will be dealt with in the next section, focusing on SA journals.

\section{Case study of South African Journals}

There are currently 253 South African journals recognized by the Government of South Africa's Department of Education (DoE) as meeting the minimum requirements for state subsidy under the policy of rewarding academics who publish in these outlets. Only 19 of those journals were CI-listed in $2004,{ }^{18}$ in an additional 15 cases the CIcoverage of SA journals was (temporarily) discontinued by Thomson Scientific during the period 1993-2003. Of all SA publications published in CI-listed journals in 2002, an estimated 30\% were disseminated through these South African journals (TIJSSEN et al., 2006). This set of DoE accredited journals provides a sufficiently large nation-wide sample for citation impact analyses across fields of science. ${ }^{19}$

Table 3. South African research specialization profiles for different information sources and scientometric indicators (publication output distribution across broad fields of science, \%)*

\begin{tabular}{lccrr}
\hline & $\begin{array}{l}\text { Medical } \\
\text { and Life }\end{array}$ & Natural Engineering & Social \\
\hline SA publication output in all CI-listed journals $(\mathrm{n} \approx 8500)^{* *}$ & 50 & 31 & 10 & 9 \\
Publication output in SA CI-listed journals $(\mathrm{n}=19)^{* * *}$ & 28 & 60 & 5 & 7 \\
Publication output in SA non-CI listed journals $(\mathrm{n}=57)^{* * *}$ & 23 & 23 & 4 & 50 \\
CI-listed citations to SA non-CI listed journals $(\mathrm{n}=88)^{* * * *}$ & 12 & 51 & 6 & 31 \\
\hline
\end{tabular}

* Source: CWTS/Thomson Science Citation Index database (edition 2005, excluding the Arts and Humanities Citation Index).Allocation of journals to fields was done by CWTS and CREST.

** Publication years 2001-2004.

*** Publication years 2001-2002.

**** Cited years 1994-2004; citing years 2002-2003 (all non-CI journals that received 1 or more citations; excluding Arts and Humanities journals).

Returning to the issue of research specialization, Table 3 displays different specialization profiles of SA science, based on either CI or non-CI sources of information. A distinct general pattern emerges from these data in which two distinct domains of scholarly communication can de discerned: (1) the CI-based literature, in which SA publication output turns out to be heavily tilted towards the medical and life

${ }^{18}$ An additional three SA journals that are indexed by Thomson Scientific in 2004 belong to research fields in the arts and humanities: South African Archaelogical Bulletin, South African Journal of Philosophy, and South African Historical Journal. Since the arts and humanities are not part of this study, these journals are excluded from further analyses and statistical tables.

${ }^{19}$ The journals attributed to the fields of sciences of arts and humanities are not included in these analyses owing to the poor coverage of such journals from countries other than the USA in the Citation Indexes. A more extensive scientometric analysis of the South African journals, including those attributed to the arts and humanities is presented in MOUTON et al. (2006). 
sciences and the natural sciences; ${ }^{20}(2)$ the non-CI literature, where the social sciences dominate the publication output. The interface between both literatures - i.e. where the 'international' CI-based research literature is citing 'local' non-CI SA research - seems to be the realm of the natural sciences and the social sciences. This outcome is not unexpected in view of SA's social sciences with its heavy emphasis on local issues and publishing in local languages. The large share of the natural sciences comes as a surprise given the importance of the international research communities, research paradigms and the dominance of English for scholarly communication within this area. This finding suggests that that significant share of highly cited SA science is not published in CI-listed journals. Part of those citations will originate from foreign research articles, thus reflecting genuine international scientific impact, part are domestic citations from SA researchers of which some are undoubtedly author selfcitations where researchers cite 'local work' in the reference list of later articles published in the internationally peer-reviewed journals. The findings presented in Table 4 provide empirical confirmation that such domestic citation flows are particularly strong in the case of the natural sciences.

Further analysis of the citations received during the years 2001-2004 by 166 SA journals (both CI-listed and non-CI) indicates that the non-CI journals account for $48 \%$ of all references within the CI-listed journal literature to SA (co)-authored research articles. ${ }^{21}$ Similarly to the AJOL-based results presented in Figure 5, the distribution of these citations is highly skewed. One of the determining factors of this skew distribution is, obviously, the journal's field of science. The medical, life, and natural sciences are characterized by large and international research communities that operate and communicate on the basis of common scientific paradigms (i.e. theories and hypotheses, research themes, methods and investigative approaches), as a result of which research articles tend to exhibit heavy citation traffic. Conversely, the other and smaller fields of science tend to include research activities of a more applied nature and/or be focused on local or regions problems or themes. Hence one would expect journals in the medical and health sciences, and in the natural sciences, to accumulate the largest quantities of citations, and those in the social science and arts and humanities the lowest numbers of citations.

\footnotetext{
${ }^{20}$ The over-representation of the medical and life sciences is not a typical African phenomenon, but rather an international one, owing to Thomson Scientific's Citation Indexes extremely high coverage of the journals in these fields of science (e.g., MOED, 2005).

${ }^{21}$ The citation data refer to cited publications that were published in the period 1980-2004.
} 
Table 4. Citation impact of South African journals: summary statistics*

\begin{tabular}{|c|c|c|c|c|c|}
\hline & $\begin{array}{l}\text { Medical and } \\
\text { Life Sciences }\end{array}$ & $\begin{array}{c}\text { Natural } \\
\text { Sciences }\end{array}$ & $\begin{array}{l}\text { Engineering } \\
\text { Sciences }\end{array}$ & $\begin{array}{c}\text { Social } \\
\text { Sciences }\end{array}$ & Share \\
\hline \multicolumn{6}{|l|}{ Citation frequency** } \\
\hline High $>250$ & $1(1)$ & $7(7)$ & & & $8 \%$ \\
\hline $100<$ Moderate $<250$ & $1(1)$ & $6(5)$ & & $2(1)$ & $8 \%$ \\
\hline $25<$ Few $<100$ & $2(1)$ & $11(1)$ & $2(1)$ & $7(1)$ & $21 \%$ \\
\hline $1<$ Very few $<25$ & 14 & 12 & 5 & 30 & $58 \%$ \\
\hline None & 1 & 2 & & 3 & $6 \%$ \\
\hline \multicolumn{6}{|c|}{ Journal Impact Factor** } \\
\hline CE-JIF $>0.5$ & & $5(5)$ & & & $7 \%$ \\
\hline $0.25<\mathrm{CE}-\mathrm{JIF}<0.5$ & $2(2)$ & $8(5)$ & 1 & 2 & $19 \%$ \\
\hline $0.1<\mathrm{CE}-\mathrm{JIF}<0.25$ & $3(1)$ & $7(1)$ & $2(1)$ & $1(1)$ & $19 \%$ \\
\hline $0<\mathrm{CE}-\mathrm{JIF}<0.1$ & 8 & $8(1)$ & 2 & $21(1)$ & $56 \%$ \\
\hline \multicolumn{6}{|c|}{ Share of SA citations $* * *$} \\
\hline$>50 \%$ & & 3 & & 1 & $13 \%$ \\
\hline $20 \%-50 \%$ & $1(1)$ & $13(10)$ & $1(1)$ & $3(2)$ & $58 \%$ \\
\hline$<20 \%$ & $2(1)$ & $5(4)$ & 1 & 1 & $29 \%$ \\
\hline
\end{tabular}

* Source: CWTS/Thomson Science Web of Science database (excluding the Arts and Humanities Citation Index). Citing years: 2002 and 2003; cited years: 1994-2002.

** Concerns 107 cited journals - i.e. the 88 non-CI journals and the 19 CI-listed ones that were attributed to broad fields. The number of CI-listed SA journals in 2004 indicated between brackets.

*** Citations originating from research articles published in CI-listed with one or more South African author addresses. The selection concerns the 31 most highly cited journals, i.e., receiving at least 25 citations during the years 2002-2003 to articles published in 1994-2002. The number of CI-listed SA journals in 2004 indicated between brackets.

Table 4 displays the summary results of the citation analyses for a subset of 165,107 cited journals - i.e. the 88 non-CI journals and the 19 CI-listed ones, classified by broad field of science. Each of these selected journals received at least one citation during the interval 1994-2002, and we were able to gather data on the annual number of publications was available during the same time-interval. ${ }^{22}$ The numbers of CI-listed journals are indicated between parentheses. The majority of the journals are cited infrequently. Although the set of 37 journals attributed to the natural sciences show a wide range in citation frequencies, most of these journals are CI-listed, none of which

22 The figures on annual publication output were retrieved by staff at CREST (Univ. Stellenbosch, South Africa) from CREST's South African Knowledgebase, Index to South African Periodicals and from SA Studies. 
collected fewer than 25 citations. It is also interesting to note that the large majority of SA's medical journals are among the lesser cited journals, with the exception of the CIlisted journals.

Although these observed differences in citation frequency reflect field-dependent phenomenon in scholarly communication, one cannot simply compare citation frequency data of journals within fields of science without taking into account the publication output magnitude of the cited journals. Naturally, citation frequency data require size-corrected normalizations to arrive at fair and robust comparisons of journal impacts. There are many computational methods to correct citation frequencies for the quantity of 'citable' publication output. One of them, the Impact Factor (IF), is particularly noteworthy and useful. ${ }^{23}$ This index is probably the prime example of a CIdependent size-corrected measure of citation impact. The IF's two-year citation window was originally designed in the 1960s to measure the short-term impact of the prestigious mainstream journals, more specifically those originating from the advanced countries, especially the USA, and gathering significant quantities of citations in such a short period of time. In contrast, most SA journals, and those other less developed countries, play a modest role in worldwide science and therefore fail to meet these criteria; publications in these journals take much more time to attract sufficient numbers of citations (if any) from the international scientific literature. In dealing these technical drawbacks, the IF's two-year citation window was expanded to eight years, while two consecutive years cited years were merged in order to reduce the possibility of large yearly fluctuations. ${ }^{24}$ This Composite Extended Journal Impact Factor (CE-JIF) is more suited to produce statistically robust measures of the international citation impact generated by SA journals in general.

We can now also address the question whether non-CI journals are also among the SA's internationally most highly cited journals. As it turns out, only six journals, each of them dealing with the natural sciences, manage to attract an average of at least 0.5 citation per article (CE-JIF $\geq 0.50$ ), each of those journals are (partially) CI-listed. Another six CI-listed SA journals have CE-JIF values less than 0.30. As for the non-CI listed journals, several of them have scores ranging from 0.25 to 0.50 . Two of them,

\footnotetext{
${ }^{23}$ The IF is computationally defined as follows: the ratio of all CI-indexed citations received in year $t$ referring to CI-indexed publications from the years $t-1$ and $t-2$ and the number of research articles published in those two years. The IF was developed by ISI (GARFIELD \& SHER, 1963), and is applied extensively for evaluating and comparing journal impact performances across the globe. Over the past decades, the IF has gradually proved to be an invaluable analytical tool for a wide variety of users, including funding agencies which use the IF do judge grantees and their publication lists, as well as university administrators and research councils for institutional evaluations of research performance.

${ }^{24}$ The third difference with respect to the IF relates to the journal self-citations, i.e., the citations from one article to another published within the same journal. Since these journal self-citations are not registered within Citation Indexes in the case of the non-CI listed journals, these self-citations are also not included in the citation counts of the CI-listed journals in order to arrive at a fair comparison of CE-JIF values of both CIlisted and non-CI listed journals.
} 
South African Journal of Enology and Viticulture and Concrete, attract an average of 0.47 citations per research article, comparable to the most highly cited SA journals. SA's most highly cited non-CI journals in AJOL have considerably lower index values: South African Forestry Journal (CE-JIF=0.13); Philosophical Papers (CE-JIF=0.12). ${ }^{25}$

In summary, no evidence is found of a clear cut distinction between a small 'elite' set of CI-listed journals that are relatively highly cited in the international literature and the large majority of poorly cited non-CI journals. The CI/non-CI dichotomy seems inadequate to categorize journals according to their international standing. This finding also raises issues with regard to how SA journals should be classified, more in particular with respect to their geographical impact. One of the key empirical questions is: to what degree do South African journals actually cater to a foreign readership and attract citations from the scientists and scholars abroad? CI-based citation data provide some valuable clues about the true nature of SA's international scientific impact. ${ }^{26}$

\section{Geographical origin of citation impact}

Citations issued by articles published in CI-listed journals may in fact refer to local scholarly communication and knowledge dissemination, rather than international knowledge flows. By calculating the shares of citations (author self-citations included ${ }^{27}$ ) originating from SA CI-listed research articles to local SA journals, one can estimate a journal's geographical impact, and gauge the degree to which the CI-based citation impact levels also reflect local impacts. The findings, summarized at the bottom of Table 4 , indicate that the majority of the citations were of SA origin in $13 \%$ of the journals; SA citations accounted for $20-50 \%$ of all citations in $58 \%$ of the journals. In only $29 \%$ of the cases do we find the impact to be predominantly international; SA citations represent less than $20 \%$ in nine journals, four of which are not CI-listed, thus indicating that in exceptional cases local journals may indeed enjoy a significant degree of international citation impact. As for the previously highlighted AJOL-indexed SA journals, Quaestiones Mathematicae received 14\% of its citations from SA authors, $35 \%$ of the citations to South African Forestry Journal are of South African origin, while these self-citations account for a mere $2 \%$ in the case of Philosophical Papers, a

\footnotetext{
25 The JIF value of Quaestiones Mathematicae could not be computed due to missing data on the annual publication production.

${ }^{26}$ SA citations in this case also include author self-citations, i.e., citations from later publications by the same author(s) published in CI-listed journals. These self-citations could not be filtered out due to lack of information about the authors listed on the cited (non-CI) publications.

${ }^{27}$ It stands to reason that a non-negligible share of the citations in CI-listed journals to SA non-CI journals is of SA origin. Notably, citations whereby SA researchers cite their own work, but also those that cite previous articles of their colleagues and co-workers, or work of other members within the SA research community. Clearly, these self-citations do not qualify as 'international scientific impact' in the narrow sense, but since they are included in reference lists of papers published in CI-listed journals, they do indirectly reflect international visibility of the cited SA science and associated researchers.
} 
journal assigned to the arts and humanities with an unexpectedly high citation impact at the international level. These outcomes certainly merit a geographical breakdown of citing sources when classifying African journals according to their international scientific impact.

\section{General observations and concluding remarks}

Most international comparative statistics on research performance relate to the production of research articles published in peer-refereed international journals, representing the most internationalized segment of mainstream scientific research. It is inevitable that research articles and citations within the internationally visible scientific literatures will underestimate the true level of African research capabilities and scientific activities. However, this is not necessarily the case for international level capabilities and activities, where researchers usually operate within environments with sufficient incentives to (also) publish their work in the CI-listed peer reviewed journals. In fact, CI-based studies rarely miss the internationally visible and leading-edge researchers and scientists in African countries, as indicated by WAAST (2001) in the case of South Africa, and SHrUm (1997) for Kenya and Ghana. The less prolific, and less visible, scientists and scholars, particularly those active in applied research and indigenous science, are much more difficult to trace, since many publish infrequently or in local science journals. Regrettably, many research publications by African researchers, especially those focused on domestic or regional African issues and problems, are not accessible through the modern ICT facilities (electronic databases, internet facilities) and are therefore often neglected in assessments of African science (e.g. NWAGWU, 2005). Africa's local journals offer a rich source of empirical data, especially in the case of African countries with comparatively few papers in journals and (sub)fields of science that are insufficiently CI-covered. So, clearly, we need to include these domestic and regional journals to arrive at a satisfactorily comprehensive coverage of relevant research literatures. Systematic quantitative analyses of the bibliographic information pertaining to internationally-oriented African journals and local journals also make for a powerful analytical tool to describe and assess African science within a cross-country comparative framework by field of subfield of science, or for specific case studies of research institutes.

Although a country's output in the international journal literature may be low, possibly even too low for statistically robust quantitative analyses (which could be used as an argument against scientometric studies for these countries), such an African country may have one or more departments at universities or (international) research institutions, that are conducting research which is highly recognized in the international arena and are producing journal articles that frequently cited within the international research literature. Adding the possibility for tracing citations between international and 
local research literatures would provide significant added value to information systems. ${ }^{28}$ Such an integrated source (an 'African Citation Index'?) would allow users to fill many of the current gaps in our knowledge of national and institutional research performance profiles within African science. Although the current information sources and quantitative indicators inevitably offer incomplete pictures of the strengths and weaknesses of African science, the results of the analyses described in this paper, present a strong case for establishing a journal-based information system that includes both internationally-oriented journals and local journals. Such a comprehensive overview of African research output offers significant added value for assessments and monitoring of national and institutional research performance within Africa.

A 'one size fits all' scientometric assessment framework, based exclusively on research publications in journals, is bound to misrepresent essential information on the background and context of research activities, as well as the existence of other relevant scientific outputs. Even if research articles in international or domestic journals are lacking altogether in certain research areas, the underlying research capacity may not have completely faded away. In many countries, a significant fraction of the (strategic or applied) scientific and engineering research is done within the private sector, or for NGOs and international donor agencies, mostly on a contract basis by specialist consultancy workers or academics. This kind of research-related activity does not really lend itself to publications in learned journals, let alone in CI-listed international journals, but tends to result in commissioned reports with a limited circulation and other types of 'grey literature'. This source of information is yet to be systematically exploited in scientometric studies of African science.

Systematic quantitative analysis of Africa's local and international research journals not only provides a much needed supplement to national R\&D surveys and case studies, but also opens up a range of possibilities for regularly monitoring both African trends in mainstream peer-reviewed science, as well as benchmarking the performances of the leading African countries with those overseas. The implementation of scientometric indicators requires a step-wise introduction in order to establish 'best practices' that augment, rather than impede, capacity-building efforts directed towards a sustainable improvements of African science. A critical issue that needs to be tackled in these assessments is the definition of 'African research', and correspondingly, 'African researchers' and 'African research articles'. The findings presented in this paper reveal a large share of internationally co-authored publications, many of which list authors from overseas. Failing to properly account for international cooperation is likely to produce an overly optimistic view of 'genuine' African research capabilities and performance.

\footnotetext{
${ }^{28}$ A significant fraction of non-journal document types (especially conference proceedings, monographs and book chapters) are also likely to be cited by research articles published in national and international journals (cf. BUTLER \& VISSER, 2006)
} 
I am very grateful to Thed van Leeuwen and Erik van Wijk (CWTS, Leiden University), as well as Johann Mouton, Nelius Boshoff, Derick van Niekerk, Lynn Lorenzen, Ricci Louw and Charline Mouton (CREST, University of Stellenbosch) for their contributions in the data gathering phase of this project. The valuable comments and suggestions made by two anonymous reviewers are also highly appreciated.

\section{References}

Albuquerque, E. (2004), Science and technology systems in less developed countries. In: MoED, H., GlänZEL, W., ScHMOCH, U. (Eds), Handbook of Quantitative Science and Technology Research: The Use of Publication and Patent Statistics in Studies of S\&T Systems. Kluwer, Dordrecht, pp. 759-778.

ARvanitis, R., WAAST, R., GAILlARD, J. (2000), Science in Africa: A bibliometric panorama using PASCAL database, Scientometrics, $47: 457-473$.

ARChiBUGI, D., CoCO, A. (2004), new indicator of technological capabilities for developed and developing countries (ArCo), World Development, 32 : 629-654.

ArChiBugi, D., CoCO, A. (2005), Measuring technological capabilities at the country level: A survey and a menu for choice, Research Policy, 34 : 175-194.

Bernardes, A., Albuquerque, E. (2003), Cross-over, thresholds and the interactions between science and technology: lessons for less developed countries, Research Policy, 32 : 867-887.

BlickestafF, J., MoravCSIK, M. (1982), Scientific output in the third world, Scientometrics, $4: 135-169$.

Butler, L., VisSER, M. (2006), Extending citation analysis to non-source items, Scientometrics, $66: 327-343$.

ChAtelin, Y., ARVANTIS, R. (1992), Representing scientific activity by structural indicators: the case of Cote D'Ivoire 1884-1968, Scientometrics, 23 : 235-247.

FRAME, J. (1980), Measuring scientific activity in lesser developed countries, Scientometrics, 2 : $133-145$.

GAILlARD, J. (1992), Use of publication lists to study scientific production and strategies of scientists in developing countries, Scientometrics, $23: 57-73$.

Gailliard, J. (1996). Science policies and cooperation in Africa, Knowledge, 14 : 212-226.

GARFIELD, E. (1983), Mapping science in the third world, Science and Public Policy, 112-127.

HASSAN, M. (2001), Can science save Africa? Science, $292: 609$.

INGWERSEN, P., JACOBS, D. (2004), South African research in selected scientific areas: Status 1981-2000, Scientometrics, $59: 405-423$.

JACOBS, D., INGWERSEN, P. (2000), A bibliometric study of the publication patterns in the sciences of South African scholars 1981-96, Scientometrics, 47 : 75-93.

KING, D. (2004), The scientific impact of nations: what different countries get for their research spending, Nature, $430: 311-316$.

KONRAD, N., WAHL, D. (1990), Science, technology and development indicators for third-world countries possibilities for analysis and grouping, Scientometrics, $19: 245-270$.

MORAVCSIK, M. (1985), Applied scientometrics: an assessment methodology for developing countries, Scientometrics, $7: 165-176$.

Moed, H. F. (2005), Citation Analysis in Research Evaluation, Springer Publishers, Dordrecht.

Mouton, J., Boshoff, N., Tusssen, R. J. W. (2006), A comprehensive analysis of South African research journals. In: GEVERS, W. et al. (Eds), Report on Strategic Approach to Research Publishing, Academy of Science of South Africa: Pretoria/Tshwane, pp. 29-59.

NSB (2006), Science and Engineering Indicators 2006, National Science Board/National Science Foundation, Arlington (VA).

Narin, F., Stevens, K., Whitlow, E. (1991), Scientific cooperation in Europe and the citation of multinationally authored papers, Scientometrics, $21: 313-323$.

Narvaez-Berthelemot, N., Russell, J. M., Arvanitis, R., WaAst, R., Gaillard, J. (2002), Science in Africa: An overview of mainstream scientific output, Scientometrics, 54 : 229-241. 
NwAGWU, W. (2005), Deficits in the visibility of African scientists: implications for developing Information and Communication Technology (ICT) capability, World Review of Science, Technology and Sustainable Development, 2 : 244-260.

Pouris, A., Richter, L. (2000), Investigation into state-funded research journals in South Africa, South African Journal of Science, 96 : 98-104.

POURIS, A. (2003), South Africa's research article record: The last ten years, South African Journal of Science, 99 : 425-428.

POURIS, A. (2005), An assessment of the impact and visibility of South African journals, Scientometrics, $62: 213-222$.

SACHS, J. (2005), The End of Poverty: Economic Possibilities for Our Time, Penguin Press.

Schmoch, U. (2005), The Knowledge Basis Of Africa - Status And Perspectives, Paper presented at the Globelics Africa Conference, Pretoria (South Africa), October $31^{\text {st }}$-November $4^{\text {th }} 2005$.

SHRUM, W. (1997), View from afar: 'Visible' productivity of scientists in the developing world, Scientometrics, $40: 215-235$.

SMART, P. (2005), Increasing the visibility of published research: African Journals OnLine, Africa Today, $52: 39-53$.

Tijssen, R. J. W., Mouton, J., Van Leeuwen, T. N., Boshoff, N. (2006), How Relevant Are Local Scholarly Journals in Global Science? A Case Study of South Africa, (Submitted for publication, 2007).

UIS (2005), What do bibliometric indicators tell us about world scientific output? Bulletin on Science and Technology Statistics, issue no 2, September 2005, UNESCO Institute for Statistics, Montreal.

WAAST, R. (2002), The State of Science in Africa : An Overview, IRD Report, Paris: Institute de Recherche pour le Développement.

World BANK (2005), Meeting the Challenge of Africa's Development: A World Bank Group Action Plan. World Bank, New York. 